\title{
Colon Targeting of Naringin for Cytoprotection against Ulcerative Colitis: In Vitro-In Vivo Study
}

\author{
Thanaa M. Borga, Elham A. Mohamed ${ }^{\mathrm{a}}$, Eman E. El Naggar ${ }^{\mathrm{a}, *}$, \\ Ahmed R. El-Sheakh ${ }^{\mathrm{b}}$, Mohammed F. Hamed ${ }^{\mathrm{c}}$ \\ ${ }^{a}$ Department of Pharmaceutics, Faculty of Pharmacy, Mansoura University, Mansoura, 35516, Egypt \\ ${ }^{b}$ Department of Phamacology, Faculty of Pharmacy, Mansoura University, Mansoura, 35516, Egypt \\ ${ }^{c}$ Department of Pathology, Faculty of Veterinary Medicine, Mansoura University, Mansoura, 33516, Egypt.
}

\begin{abstract}
Naringin has low oral bioavailability because of its degradation at the upper gut. Therefore, this study involved formulation of compression-coated tablets of naringin using mixtures of Eudragit L100-55 (EUD-L) and hydroxypropyl methylcellulose (HPMC) at two different respective weight ratios of 95:5 (F1) and 90:10 (F2). Evaluation of the tablets regarding drug content, physical characters, swelling and in vitro release has been performed. Kinetic analysis of release data was done. The effects of the selected tablet formulation on indomethacin-induced colitis in rabbits were investigated. The results showed that average values of drug content were $99.66 \pm 2.18$ and $104.00 \pm 1.58$ for F1 and F2, respectively. The prepared tablets showed good hardness $\left(7.97-8.85 \mathrm{~kg} / \mathrm{cm}^{2}\right)$ and friability (less than 1\%) that were within the pharmacopeal range. The increase in HPMC content to $10 \%$ of the coating weight (F2) resulted in higher swelling degree of the coated tablets. Therefore, more retarded release and colon targeting were obtained with higher HPMC content (F2) as clarified by percentage drug release of $17.80 \pm 2.70$ after $5 \mathrm{~h}$. In accordance, this tablet formulation provided effective protection against indomethacin-induced colitis in rabbits as confirmed by normal mucosa of colon, significant $(p<0.05)$ decrease in levels of serum pANCA and colonic TNF- $\alpha$.
\end{abstract}

Keywords: Compression coated Tablets, Colon targeting, Eudragit L100-55, Hydroxypropyl methylcellulose, Naringin, Ulcerative colitis.

\section{Introduction}

The oral route is commonly used to administer drugs because of better patient compliance, easier administration and relatively lower production cost than other routes [1,2]. Site-specific delivery systems for targeting drugs to the colon have been widely investigated during the last decade. These drug delivery systems have been utilized to deliver drugs locally in the colon to treat diseases like Crohn's disease, ulcerative colitis, irritable bowel syndrome and constipation as well as to provide a systemic action of various drugs such as proteins, antiasthmatics, antihypertensives and antidiabetics [3, 4]. Treatment of ulcerative colitis with glucocorticosteroids and immunosuppressive drugs may cause serious side effects [5, 6]. Naringin exhibited several pharmacological activities such as anti-inflammatory, cardiovascular, hypolipidemic, antiatherosclerotic, antidiabetic, neuroprotective, hepatoprotective, and anticancer activities [7, 8]. Naringin has shown some gastroprotection against colitis in mice [9]. However, cleavage due to the harsh $\mathrm{pH}$ and enzymatic conditions of the upper gastrointestinal tract resulted in low and irregular absorption of this drug following oral administration $[10,11,12]$.

Site-specific drug delivery systems for colon targeting should hinder the drug release and absorption in upper gut but allow drug release in the colon [13]. The local treatment of inflammatory bowel diseases, such as ulcerative colitis is highly challenging since it requires minimal release in the upper gastro-intestinal tract (GIT) and time-controlled release within the colon [14, 15]. Coating of tablets with Eudragit-L100-55 (EUD-L) can protect the active drug from gastric fluid and possibly the proximal part of the small intestine [16]. Addition of water-insoluble polymer as hydroxypropyl methylcellulose (HPMC) to EUD-S100 coats has been used for colonic delivery of diclofenac sodium [17].

When compared to the traditional liquid coating process, direct compression coating of tablets for colon targeting is more convenient particularly for large scale production as it is solvent free, less timeconsuming and inexpensive [18].

In this study, directly compressed coated tablets of naringin were prepared using coating mixtures of EUD-L and HPMC. The prepared tablets were evaluated with respect to drug content, hardness, friability, swelling, and in vitro release in media with different $\mathrm{pH}$ values $(1.2,6.8$, and 7.4$)$ up to $8 \mathrm{~h}$ to select an optimized formula. As well, the protection of the selected tablet formulation against indomethacin-induced colitis in rabbits was investigated. 


\section{Materials and method}

Naringin and hydroxypropyl methylcellulose (HPMC K100) were purchased from Sigma-Aldrich Co., St. Louis, USA. Eudragit L100-55 (EUD-L) was obtained from Evonic Rhom GmbH, Darmstat, Germany. Indomethacin was supplied by Kahira Pharmaceuticals \& Chemical Industries Co., Cairo, Egypt. Rabbit antiantineutrophilic perinuclear antibodies (pANCA) ELISA Kit was purchased from My biosource, USA. Avicel pH 101 was obtained from Eipico Pharmaceutical Chemicals Co., Cairo, Egypt. Magnesium stearate was purchased from Acros organics, New Jersy, USA. Talc was purchased from El-Nasr Pharmaceutical Chemicals Co., ADWIC, Cairo, Egypt. Other chemicals used were of fine analytical grade.

\subsection{Preparation of naringin core and compression coated tablets}

Passage of naringin through $200 \mu \mathrm{m}$ sieve was followed by mixing with avicel pH 101 using a mortar and pestle and then lubrication with a 2:1 blend of talc $(2 \% \mathrm{w} / \mathrm{w})$ and magnesium stearate $(1 \% \mathrm{w} / \mathrm{w})$. An amount of $180 \mathrm{mg}$ of the mixture was directly compressed (Erweka, Germany) to give a core tablet containing $125 \mathrm{mg}$ naringin with hardness between 5 and $6 \mathrm{~kg} / \mathrm{cm}^{2}$.

The core tablets were coated with EUD-L and HPMC at two weight ratios of 95:5 and 90:10, respectively, maintaining the core: coat ratio at 1:2, Table1. The polymers were passed through $200 \mu \mathrm{m}$ sieve, mixed using a mortar and pestle for $10 \mathrm{~min}$ and then lubricated with talc $(2 \% \mathrm{w} / \mathrm{w})$ and magnesium stearate $(1 \%$ w/w). A quantity of $180 \mathrm{mg}$ of the polymers mixture was put into the die, the tablet core was placed at the center and finally another weight of $180 \mathrm{mg}$ of the polymers mixture was added to be directly compressed (Erweka, Germany). The tablet hardness range was $8-10 \mathrm{~kg} / \mathrm{cm}^{2}$.

Table (1): Composition of tablet coats

\begin{tabular}{|c|c|c|c|c|}
\hline $\begin{array}{c}\text { Formula } \\
\text { code }\end{array}$ & $\begin{array}{c}\text { Eudragit L100-55 } \\
\text { (EUD-L) }\end{array}$ & $\begin{array}{c}\text { Hydroxypropyl } \\
\text { methylcellulose K100 } \\
\text { (HPMC) }\end{array}$ & $\begin{array}{c}\text { Magnesium } \\
\text { stearate }\end{array}$ & Talc \\
\hline F1 & 331.74 & 17.46 & 3.6 & 7.2 \\
\hline F2 & 314.28 & 34.92 & 3.6 & 7.2 \\
\hline
\end{tabular}

\subsection{Characterization of naringin tablets}

Physical characters of the tablets were studied according to procedures reported in US pharmacopoeia [19]. The drug content in the tablets was determined in triplicate. An amount of the ground ten tablets equivalent to $125 \mathrm{mg}$ of naringin was mixed with methanol, sonicated then the final volume was adjusted with phosphate buffer (PB) pH 7.4 to $500 \mathrm{~mL}$. The sonicated mixture was filtered and diluted. Spectrophotometric analysis (UV/VIS spectrophotometer, Jasco, Japan) was done for drug content at $282 \mathrm{~nm}$.

\subsection{Swelling studies}

Each tablet was individually weighed $\left(\mathrm{W}_{1}\right)$ and placed into a beaker containing $200 \mathrm{~mL}$ of $0.1 \mathrm{~N} \mathrm{HCl}$ kept at $37 \pm 0.5^{\circ} \mathrm{C}$. At time intervals of 30,60 and $120 \mathrm{~min}$, the tablet was reweighed $\left(\mathrm{W}_{2}\right)$ after a careful removal of the medium on the surface. The same process was followed in PB pH 6.8 and 7.4 using the same tablet. The mean weights of tablets were determined after repeating the process twice to calculate the percent swelling according to the following relation $[2,20]$ :

$$
\text { Swelling index }=\mathrm{W}_{2}-\mathrm{W}_{1} / \mathrm{W}_{1} \times 100
$$

\subsection{In vitro drug release}

The drug release from the coated tablets was studied using USP apparatus I (Dissolution Apparatus USP Standards, Scientific, DA-6D, Bombay, India). The dissolution medium $(500 \mathrm{~mL})$ was kept at $37 \pm 0.5^{\circ} \mathrm{C}$ and stirred at $100 \mathrm{rpm}$. The release medium was $0.1 \mathrm{~N} \mathrm{HCl}(\mathrm{pH} 1.2)$ for $2 \mathrm{~h}, \mathrm{~PB} \mathrm{pH} 6.8$ for $3 \mathrm{~h}$, and finally $\mathrm{PB}$ $\mathrm{pH} 7.4$ [21, 22]. Samples were withdrawn at certain time intervals up to $8 \mathrm{~h}$ and replaced by fresh medium. The samples were filtered and diluted to be analyzed spectrophotometrically at $282 \mathrm{~nm}$ (UV/VIS spectrophotometer, Jasco, Japan).

\subsection{Kinetic modeling of drug release data}

In vitro release data were analyzed according to zero-order, first-order [23], diffusion-controlled release mechanism [24] and Korsmeyer-Peppas kinetic model [25]. The model with the highest correlation coefficient $\left(\mathrm{r}^{2}\right)$ was considered to describe the drug release. 


\subsection{In vivo evaluation of the optimized naringin tablets}

\subsubsection{Experimental animal protocol}

Male New Zealand rabbits $(\approx 2.5 \mathrm{~kg})$ were used in this study in accordance with the ethical principles of the scientific committee of Faculty of Pharmacy, Mansoura University, Egypt for the use of experimental animals. As discussed later, the selected tablet formula for in vivo study was that coated with a combination of 90\% EUD-L and 10\% HPMC (F2), Table1.

Eighteen rabbits were randomly divided into three groups, each consisted of six animals. The animals were fasted but allowed a free access to water for $24 \mathrm{~h}$ before the day of the experiment. Group I received saline. Group II was given $8 \mathrm{mg} / \mathrm{kg}$ indomethacin suspension in $1 \%$ sodium carboxymethylcellulose orally (untreated colitis) [26]. Group III was given 10\% HPMC coated tablets (F2) for five days, then a single intragastric dose of $8 \mathrm{mg} / \mathrm{kg}$ indomethacin in $1 \% \mathrm{SCMC}$ was given at the fifth day $2 \mathrm{~h}$ after coated tablet administration.

\subsubsection{Measurement of serum pANCA}

Twenty-four hours following indomethacin administration, collection and centrifugation of blood samples were done to separate sera to be stored at $-80{ }^{\circ} \mathrm{C}$ to be assayed for perinuclear antineutrophil cytoplasmic antibodies (pANCAs) using the kit of My bio source, USA.

\subsubsection{Histopathological investigation of colon}

At the end of the animal study, rabbits were sacrificed and pieces of colon were cleaned, washed with $0.9 \%(\mathrm{w} / \mathrm{v})$ saline solution and kept in $10 \%(\mathrm{v} / \mathrm{v})$ formalin in saline for histopathological investigation. Sections of $5 \mu \mathrm{m}$ were stained with hematoxylin and eosin.

\subsubsection{Colonic levels of TNF-a}

Staining was done using the histostain bulk kit-Invitrogen Lab-SA detection system. Deparaffinization was accomplished by EZ Prep solution. Citrate buffer of $\mathrm{pH} 6.0$ was used for antigen retrieval. DAB inhibitor $\left(3 \% \mathrm{H}_{2} \mathrm{O}_{2}\right.$ endogenous peroxidase) was blocked for $5 \mathrm{~min}$ at room temperature. Sections were incubated with anti-TNF- $\alpha$ antibody (Boster Biological Technology dilution 1/100) for 40 min at room temperature, then with the antibody of Universal HRP Multimer for $8 \mathrm{~min}$ at $37^{\circ} \mathrm{C}$. Slides were treated with $\mathrm{DAB}+\mathrm{H}_{2} \mathrm{O}_{2}$ substrate for $8 \mathrm{~min}$, followed by hematoxylin and the bluing reagent counterstain at $37^{\circ} \mathrm{C}$. Phosphate buffer saline (PBS) was used for washing. The staining intensity of positively stained cells was evaluated and immunostaining was scored [27]. Controls were prepared by staining without employment of primary antibody.

\subsection{Statistical analysis}

Statistical analysis of the results was accomplished applying One-way ANOVA and then TukeyKramer multiple comparisons test at a significance level of $p<0.05$ employing Graphpad prism software (version 5.00; Graphpad software, San Diego, CA, USA).

\section{Results and discussion}

\subsection{Characterization of the compression-coated tablets}

The physical characteristics and drug content uniformity of the coated tablets are represented in Table 2. The tablets showed good weight uniformity. Average hardness values and friability (less than $1 \%$ ) for the tested coated tablets were within the pharmacopeal limits [19]. The studied tablets exhibited uniform drug content within the pharmacopeal range of $90-110 \%$ [19].

Table (2): Drug content and physical characters of naringin tablets

\begin{tabular}{|c|c|c|c|c|c|c|}
\hline \multirow{2}{*}{ Formula code } & \multicolumn{6}{|c|}{ Mean \pm SD } \\
\cline { 2 - 7 } & Weight uniformity $(\mathrm{mg})$ & $\begin{array}{c}\text { Thickness } \\
(\mathrm{mm})\end{array}$ & $\begin{array}{c}\text { Diameter } \\
(\mathrm{mm})\end{array}$ & $\begin{array}{c}\text { Hardness } \\
\left(\mathrm{Kg} / \mathrm{cm}^{2}\right)\end{array}$ & $\begin{array}{c}\text { Friability } \\
\%\end{array}$ & $\begin{array}{c}\text { Drug content } \\
(\%)\end{array}$ \\
\hline F1 & $541.28 \pm 1.60$ & $3.56 \pm 0.04$ & $12.11 \pm 0.07$ & $8.85 \pm 0.33$ & $0.58 \pm 0.08$ & $99.66 \pm 2.18$ \\
\hline F2 & $540.22 \pm 1.42$ & $3.75 \pm 0.01$ & $12.09 \pm 0.08$ & $7.97 \pm 0.54$ & $0.58 \pm 0.05$ & $104.00 \pm 1.58$ \\
\hline
\end{tabular}




\subsection{Swelling study}

The swelling behavior of the coated tablets has been examined, Figure 1. The increase in the polymer concentration from 5\% to $10 \%$ enhanced the coat swelling. At $\mathrm{pH} \mathrm{1.2,} \mathrm{high} \mathrm{swelling} \mathrm{percentages} \mathrm{have} \mathrm{been}$ observed probably due to the rapid hydration and the high affinity to the test medium. At $\mathrm{PB} \mathrm{pH} 6.8$, the increase in the swelling rate continued being the maximum at $2.5 \mathrm{~h}$. On the other hand, a sharp decrease in the swelling of coatings has been observed at $\mathrm{PB} \mathrm{pH} 7.4$ beyond the fifth hour that could suggest the erosion of these swollen matrices.

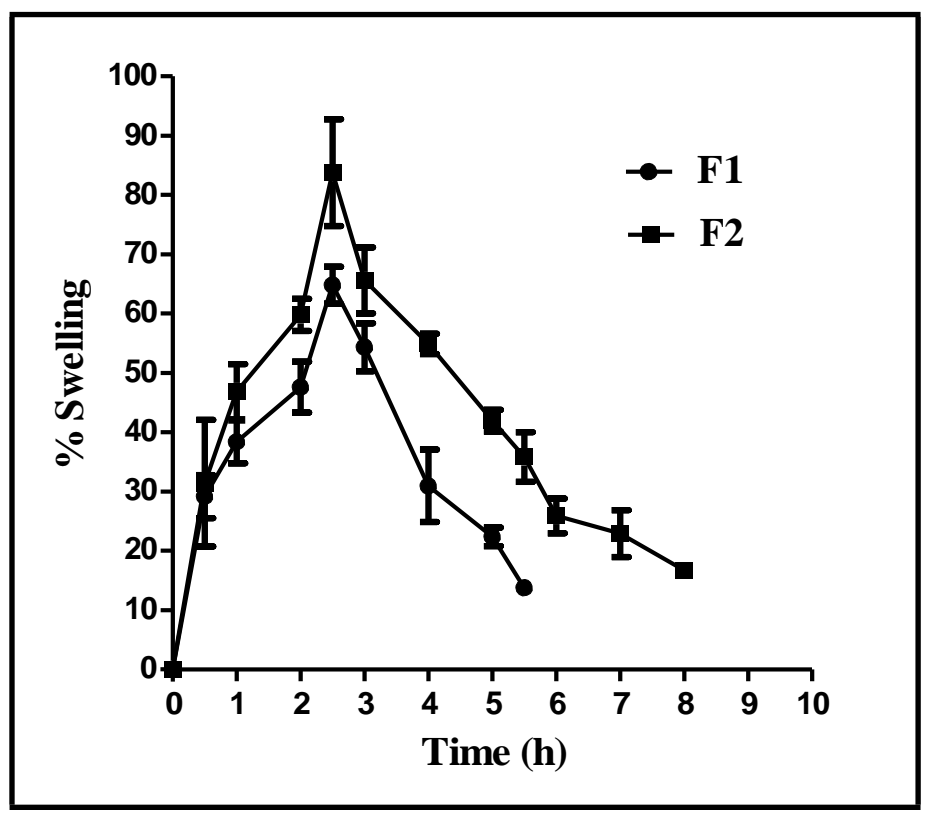

Figure 1: Swelling behavior of naringin tablets coated with 5\% HPMC (F1) and 10\% HPMC (F2) in $0.1 \mathrm{~N} \mathrm{HCl}$

\subsection{In vitro release study}

for $2 \mathrm{~h}, \mathrm{~PB} \mathrm{pH} 6.8$ for $3 \mathrm{~h}$, and $\mathrm{PB} \mathrm{pH} 7.4$ for $3 \mathrm{~h}$.

The results of in vitro release of naringin from tablets coated with Eud L-100-55 and HPMC are shown in Figure 2. Generally, the release was insignificant $(0.37 \% \pm 0.13)$ during the first two hours in $0.1 \mathrm{~N} \mathrm{HCl}$. When HPMC concentration in the coat was 5\% (F1), drug release continued to be low up to the first hour and half in $\mathrm{PB} \mathrm{pH} \mathrm{6.8,} \mathrm{and} \mathrm{then} \mathrm{it} \mathrm{increased} \mathrm{reaching} 86.42 \% \pm 1.33$ after $5 \mathrm{~h}$. On the other hand, coating containing $10 \%$ HPMC showed retarded release in $\mathrm{PB}$ pH 6.8 up to $5 \mathrm{~h}(17.80 \% \pm 2.69)$. The cumulative $\%$ release less than $20 \%$ after $5 \mathrm{~h}$ has been used as indicative of colon targeting $[28,29]$. As a result, tablets coated with $10 \%$ HPMC together with 90\% EUD-L (F2) have been selected to investigate the protection activity of naringin against indomethacin-induced colitis in rabbits.

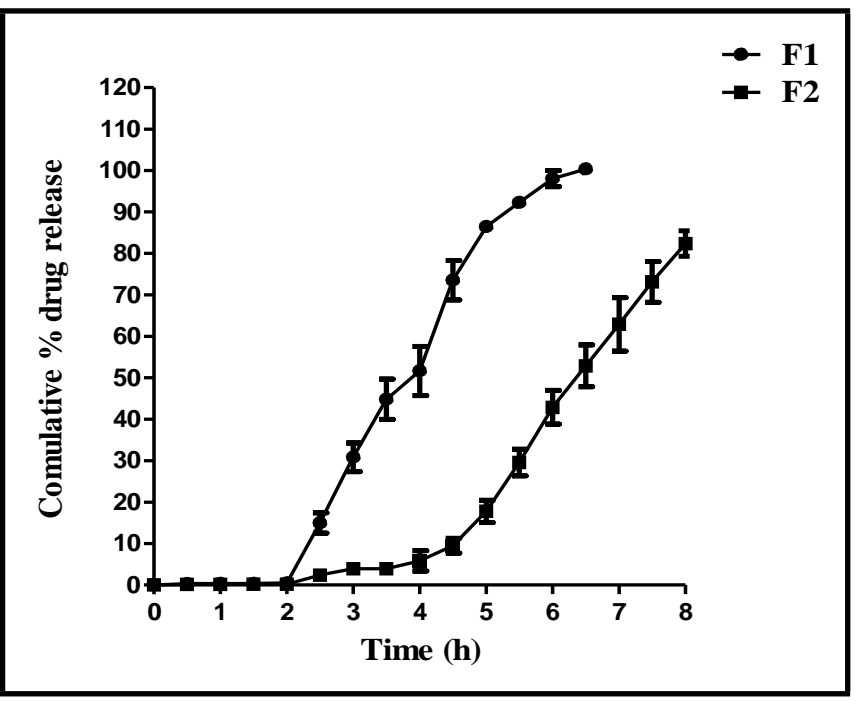

Figure 2: In vitro drug release of naringin tablets coated with 5\% HPMC (F1) and 10\% HPMC (F2) in $0.1 \mathrm{~N}$ $\mathrm{HCl}$ for $2 \mathrm{~h}, \mathrm{~PB} \mathrm{pH} 6.8$ for $3 \mathrm{~h}$, and $\mathrm{PB} \mathrm{pH} 7.4$ for $3 \mathrm{~h}$. 


\subsection{Release kinetics}

According to Table 3, the release mechanism fitted zero order kinetics. According to KorsmeyerPeppas model, $\mathrm{n} \leq 0.5$ may indicate Fickian diffusion and values of ( $\mathrm{n}$ ) between 0.5 and 1 correspond to nonFickian release [25]. At pH 1.2, Fickian release mechanism characterized by diffusion described the drug release from both tablet formulations that may be explained by the high polymer swelling rates (Figure 1). While, nonFickian release mechanism controlled by both diffusion and erosion can be assumed at pH 6.8 and 7.4 that could cause the higher release at these media.

Table 3: Kinetic modeling of drug release data

\begin{tabular}{|c|c|c|c|}
\hline \multirow{2}{*}{ Dissolution medium } & \multirow{2}{*}{ Kinetic model } & F1 & $\mathrm{F} 2$ \\
\hline & & $\mathrm{r}^{2}$ & $\mathrm{r}^{2}$ \\
\hline \multirow{6}{*}{$0.1 \mathrm{~N} \mathrm{HCL}$} & Zero order & $\underline{0.918}$ & $\underline{0.923}$ \\
\hline & First order & 0.918 & 0.927 \\
\hline & Diffusion & 0.877 & 0.870 \\
\hline & \multicolumn{3}{|c|}{ Korsmeyer } \\
\hline & $\mathrm{n}$ value & 0.384 & 0.332 \\
\hline & mechanism & Fickian & Fickian \\
\hline \multirow{6}{*}{ PB pH 6.8} & Zero order & $\underline{0.988}$ & $\underline{0.797}$ \\
\hline & First order & 0.913 & 0.782 \\
\hline & Diffusion & 0.968 & 0.707 \\
\hline & \multicolumn{3}{|c|}{ Korsmeyer } \\
\hline & $\mathrm{n}$ value & 0.963 & 0.999 \\
\hline & mechanism & Non Fickian & Non Fickian \\
\hline \multirow{6}{*}{$\mathrm{BP}$ pH 7.4} & Zero order & $\underline{0.988}$ & $\underline{0.997}$ \\
\hline & First order & 0.937 & 0.976 \\
\hline & Diffusion & 0.973 & 0.995 \\
\hline & \multicolumn{3}{|c|}{ Korsmeyer } \\
\hline & $\mathrm{n}$ value & 0.954 & 0.569 \\
\hline & mechanism & Non Fickian & Non Fickian \\
\hline
\end{tabular}

\subsection{Histopathological evaluation of rabbit colon}

The colon of normal group (I) showed normal mucosa and submucosa, Figure 3A. Administration of indomethacin to group II resulted in ulceration of entire thickness of mucosa, Figure 3B. On the other hand, group III that received naringin tablet coated with 10\% HPMC showed gastroprotection as indicated by normal mucosa with some infiltration in the submucosa, Figure $3 \mathrm{C}$. These results may be explained on the basis that the release retardation imparted by tablets coated with 10\% HPMC provided minimal gastric and intestinal absorption but allowed high drug release in the colon. The successful use of compression coated tablets of budesonide in treatment of ulcerative colitis has been documented [30].
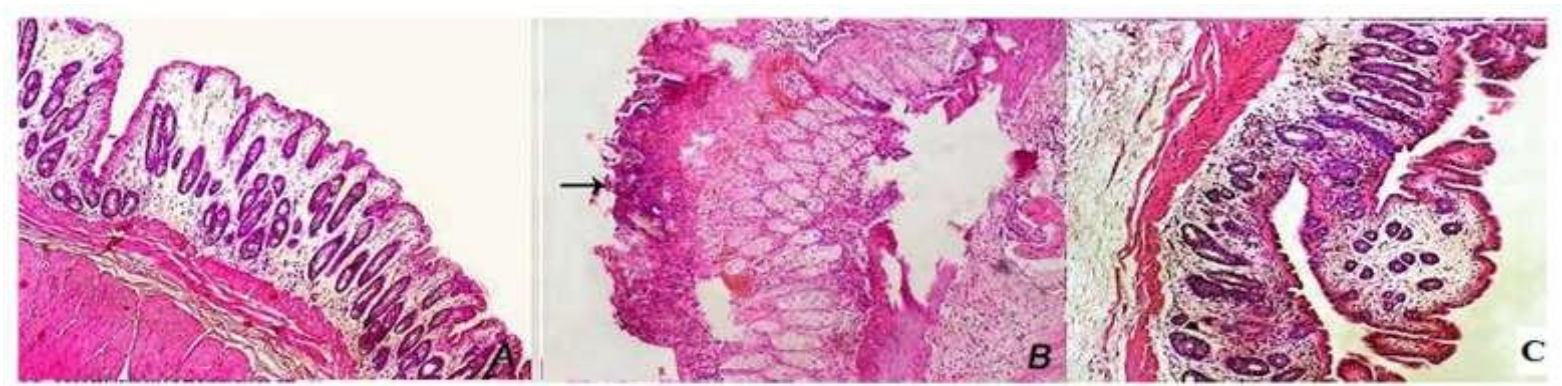

Figure 3. Photomicrographs of hematoxylin and eosin stained paraffin sections of rabbit colonic tissues (100x) showing normal mucosa and submucosa in normal group (I) (A), ulceration of superficial mucosa (arrow) in colitis untreated group (II) (B), normal mucosa with some infiltration in the submucosa in group (III) treated with $10 \%$ HPMC coated tablets (C). 


\section{Colon Targeting of Naringin for Cytoprotection against Ulcerative Colitis: In Vitro-In Vivo Study}

\subsection{Effect of naringin on pANCA serum level}

In comparison with colitis untreated group (II), serum levels of pANCA were significantly $(p<0.05)$ lower in rabbits received naringin tablets coated with 10\% HPMC (F2, group, III), Table 5. These results suggest such coated tablets as a promising colon targeting delivery system of naringin for protection against indomethacin-induced colitis in rabbits.

Table 5: Serum levels of pANCA in rabbits

\begin{tabular}{|c|c|}
\hline Treatment group & pANCA serum level $(\mathrm{ng} / \mathrm{mL})$ \\
\hline II (Indomethacin; 8mg/kg) & $12.59 \pm 0.69$ \\
\hline III (HPMC; F2) & $9.08 \pm 0.40 \#$ \\
\hline
\end{tabular}

Data are represented as mean $\pm \operatorname{SEM}(\mathrm{n}=6)$.

\# Significantly different compared to colitis untreated group (II) $(p<0.05)$

\subsection{Effect of naringin on colonic TNF- $\alpha$ levels:}

The normal group (I) exhibited faint immunostaining indicating minimal immunoreactivity, Figure 4A. The colitis untreated group (II) showed strong immunoreactivity in the form of scattered fine brown granules, Figure 4B. On the other hand, rabbits received 10\% HPMC coated tablets (group III) showed highly reduced TNF- $\alpha$ content than that of colitis untreated group (II), Figure 4C. The levels of colonic TNF- $\alpha$ were significantly $(p<0.05)$ high in colitis untreated group (II) compared to normal group (I), Table 6 . While, the reduction in colonic TNF- $\alpha$ obtained on pretreatment with coated naringin tablets was significant $(p<0.05)$ relative to colitis untreated group (II).

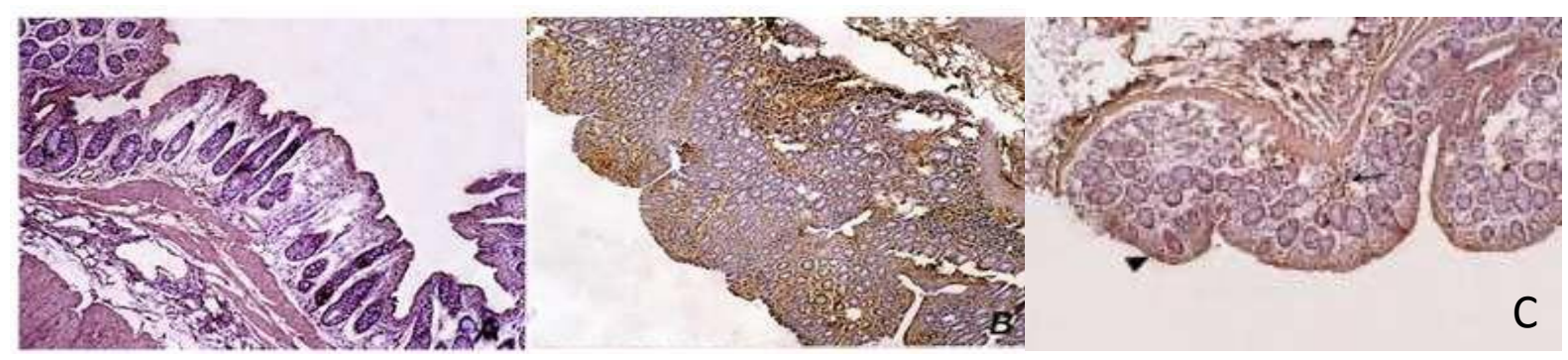

Figure 4. Immunohistochemical evaluation of TNF- $\alpha$ in all studied groups (100x) showing negative immunostain for TNF $\alpha$ in normal group (I) (A), strong positive immunoreactivity in submucosa in colitis untreated group II (B) less positive immunoreactivity limited to epithelial lining mucosa and endothelial lining blood vessels (arrow) in group III administered 10\% HPMC coated tablets (C).

Table 6: Effect of naringin tablets on colonic TNF $\alpha$ scoring

\begin{tabular}{|c|c|}
\hline Treatment group & Scores of TNF- $\alpha$ ) \\
\hline Group I (control; no drug) & $3.25 \pm 0.87$ \\
\hline Group II (indomethacin; $8 \mathrm{mg} / \mathrm{kg}$ ) & $93.25 \pm 3.91^{*}$ \\
\hline Group III (10\% HPMC; F2) & $28.75 \pm 4.04^{*} \#$ \\
\hline
\end{tabular}

Data are represented as mean \pm SEM $(n=6)$.

* Significantly different compared to normal control group (I) $(p<0.05)$

\# Significantly different compared to colitis untreated group (II) $(p<0.05)$

\section{Conclusion}

The low cumulative percent drug release $(<20 \%)$ from compression coated tablets based on $10 \%$ HPMC and 90\% EUD-L at gastric and intestinal $\mathrm{pH}$ indicated a successful colon targeting of naringin. This was confirmed by normal mucosa on histopathological examination and significant $(p<0.05)$ decrease in both serum levels of pANCA and colonic levels of TNF- $\alpha$. The swelling of HPMC coated tablets at gastric and intestinal media ( $\mathrm{pH} 1.2$ and 6.8, respectively) could account for the delayed drug release at these media and expected colon targeting. Thus, compression coated tablets based on 10\% HPMC and 90\% EUD-L can be suggested as a promising colon targeting system of naringin for cytoprotection against ulcerative colitis.

\section{Conflicts of interest}

The authors declare no conflicts of interest. 


\section{References}

[1]. Barbara L., Teresa C., Federica B., Isabella O., and Vittorio Z., PH-sensitive polymeric physical- mixture for possible site specific delivery of ibuprofen, Eur J Pharm Biopharm, 55, 2003, 199- 202.

[2]. Yusif R. M., Abu Hashim I. I., Mohamed E. A., and Badria F. A., Gastroretentive matrix tablets of Boswellia Oleogum resin: preparation, optimization, in vitro evaluation, and cytoprotective effect on indomethacin-induced gastric ulcer in rabbits, AAPS PharmSciTech.17, 2015, 328-338.

[3]. Oluwatoyin A. O., and John T. F., In vitro evaluation of khaya and albizia gums as compression coating for drug targeting to the colon, J Pharm Pharmacol, 57, 2005, 63-168.

[4]. Philip A K, Dabas S, and Pathak K, Optimized prodrug approach: a means for achieving enhanced anti-inflammatory potential in experimentally induced colitis, J Drug Target, 17, 2009, 235-241.

[5]. Hagar H. H., El-Medany A., El-Eter E., and Arafa M., Ameliorative effect of pyrrolidinedithiocarbamate on acetic acid-induced colitis in rats, Eur J of Pharmacol, 554, 2007, 69-77.

[6]. Shanahan F., Inflammatory bowel disease: immunodiagnostics, immunotherapeutics, and ecotherapeutics, Gastroenterology, 120, 2001, 622-635.

[7]. Benavente-García O., and Castillo J., Update on uses and properties of citrus flavonoids: new findings in anticancer, cardiovascular, and anti-inflammatory activity, J Agric Food Chem, 56, 2008, 6185-6205.

[8]. Chanet A., Milenkovic D., Manach C., Mazur A., and Morand C., Citrus flavanones: what is their role in cardiovascular protection? J Agric Food Chem., 60, 2012, 8809- 8822.

[9]. Amaro M. I., Rocha J., Vila-Real H., Eduardo-Figueira M., Mota-Filipe H., Sepodes B., and Ribeiro M. H., Anti-inflammatory activity of naringin and the biosynthesised naringenin by naringinase immobilized in microstructured materials in a model of DSSinduced colitis in mice, Food Res Int., 42, 2009, 1010-1017.

[10]. Choudhury R., Chowrimootoo G., Srai K., Debnam E., and Rice Evans C. A., Interactions of the flavonoid naringenin in the gastrointestinal tract and the influence of glycosylation, Biochemical and Biophysical Research Communications, 265, 1999, 410415 .

[11]. Hsiu S. L., Huang T. Y., Han Y. C., Ching D. H., and Lee Chao P. D., Comparison of metabolic pharmacokinetics of naringin and naringenin in rabbits, Life Science, 70, 2002, 1481-1489.

[12]. Lauro M. R., De Simone F., Sansone F., Iannelli P., and. Aquino R. P, Preparations and release characteristics of naringin and naringenin gastro-resistant microparticles by spray-drying, J Drug Del Sci Tech., 17 (2), 2007, 119-124.

[13]. Akala E. O., Elekwachi O., Chase V., Johnson H., Marjorie L., and Scott K., Organic redox initiated polymerization process for the fabrication of hydrogel for colon specific drug delivery, Drug Dev Ind Pharm, 29, 2003, 375-386.

[14]. Klotz U., and Schwab M., Topical delivery of therapeutic agents in the treatment of inflammatory bowel disease, Advanced Drug Delivery Reviews, 57, 2005, 267- 279.

[15]. Karrout Y., Neut C., Wils D., Siepmann F., Deremaux L., Desreumaux P., and Siepmann J., Novel polymeric film coatings for colon targeting: How to adjust desired membrane properties, Int J Pharm, 371, 2009, 64-70.

[16]. Rujivipat S., and Bodmeier R., Improved drug delivery to the lower intestinal tract with tablets compression-coated with enteric/nonenteric polymer powder blends, EurJ Pharm Biopharm, 76, 2010, 486-492.

[17]. Chickpetty S. M., Baswaraj R., and Nanjwade B. K., Studies on development of novel combined time and pH dependent solventless compression coated delivery systems for colonic delivery of diclofenac sodium, Asian Journal of Pharmaceutical and Clinical Research, 3, 2010, 110-113.

[18]. Vemula S. K., and Veerareddy P. R., Development, evaluation and pharmacokinetics of time-dependent ketorolac tromethamine tablets, Exp Opin Drug Deliv, 10, 2013, 33-45.

[19]. USP 34- NF 29. "The united states pharmacopeia", 34th, The National formulary 29th. The United States Pharmacopeial Convention, Twin Brook Parkway, Rockville, MD, 2011, pp.705-706.

[20]. Tadros M. I., Controlled-release effervescent floating matrix tablets of ciprofloxacin hydrochloride: development, optimization and in vitro-in vivo evaluation in healthy human volunteers, Eur J Pharm Biopharm., 74, 2010, 332-339.

[21]. Krishnaiah Y. S., Bhaskar Reddy, V. Satyanarayana, and R. S. Karthikeyan, Studies on the development of oral colon targeted drug delivery systems for metronidazole in the treatment of amoebiasis, Int J Pharm., 236, 2002, 43-55.

[22]. Akhgari A., Sadeghi F. P. R., and Garekani H. A., Combination of time-dependent and pH dependent polymethacrylates as a single coating formulation for colonic delivery of indomethacin pellets, Int J Pharm, 320, 2006, 137-142.

[23]. Martin A., Bustamante P., and Chun A. H. C., Kinetics In: Physical Pharmacy, (Philadelphia: lea and Febiger, (1993) 284-323.

[24]. Higuchi T., Mechanism of sustained action medication, J Pharm Sci, 52, 1963, 1145-1149.

[25]. Ritger P. L., and Peppas N. A., Simple equation for description of solute release: part 1, Fickian and non Fickian release from non swellable devices in the form of slab, spheres, cylinders or disk, $J$ Cont Rel, 5, 1987, 23-36.

[26]. Wang W., Liu Q., Wang C., Meng Q., Kaku T., and Liu K., Effects of JBP485 on the expression and function of PEPT1 in indomethacin-induced intestinal injury in rats and damage in Caco-2 cells, Peptides, 32, 2011, 946-955.

[27]. Fahmy M., Mansure J. J., Brimo F., Yafi F. A., Segal R., Althunayan A., Hicks J., Meeker A., Netto G., and Kassouf W., Relevance of the mammalian target of rapamycin pathway in the prognosis of patients with high-risk non-muscle invasive bladder cancer, Hum Pathol., 44, 2013, 1766-1772.

[28]. Rama Prasad Y. V., Krishnaiah Y. S. R., and Satyanarayana S., In vitro evaluation of guar gum as a carrier for colon specific drug delivery, J Control Release, 51, 1998, 281 - 287.

[29]. Asghar L. F. A., Chure C. B., and Chandran S., Colon specific delivery of indomethacin: effect of incorporating pH sensitive polymers in xanthan gum matrix bases, AAPS Pharm SciTech, 10 (2), 2009, 418-429.

[30]. Yehia S. A., Elshafeey A. H., Sayed I., and Shehata A. H., Optimization of budesonide compression-coated tablets for colonic delivery, AAPS PharmSciTech., 10 (1), 2009, 147-157. 